\title{
O direito frente ao mal radical: a hipérbole kantiana do povo de demônios*
}

\author{
Adelino Braz \\ Doutor em Filosofia - Universidade de Paris I \\ Panthéon-Sorbonne / NoSoPhi
}

Resumo: Através da hipérbole do povo de demônios, Kant mostra como o direito tem o poder de neutralizar o egoísmo desde o ponto de vista da ação exterior e constituir assim um estado civil. No entanto, este corresponde a um estado de natureza ética, revelando assim que a comunidade jurídica pode ser constituída sem que seja eliminado o mal radical. Dessa forma, o direito é moral sem no entanto ser ético.

Palavras-chaves: direito, ética, mal, estado civil, estado de natureza.
Abstract: Through the hyperbole of the people of devils Kant shows how right has the power to neutralize selfishness from the point of view of external action and thereby constitute a civil state. However, this state corresponds to a state of natural ethics, revealing that a juridical community can be formed withour eliminating radical evil. Therefore, right is moral without being ethical.

Keywords: right, ethics, evil, civil state, natural state.

No texto Para uma paz perpétua, de 1785, Kant, tratando da coexistência exterior das liberdades, nota que uma constituição aplicável a um povo de demônios pode ser concebida se esses seres forem dotados de entendimento: "Uma multitude de seres razoáveis desejam todos, para a sua conservação, leis universais, embora cada um tenha uma inclinação secreta para se dispensar da lei”. ${ }^{1}$ Esta posição merece um duplo nível de leitura. Por um lado, Kant insiste aqui na força coercitiva do direito, condição necessária para construir uma comunidade de liberdades exteriores. De fato, o direito público, através da justiça distributiva, permite ao direito privado, e nesse caso à justiça comutativa, ser eficaz. Por outro lado, o

* Artigo originalmente publicado na Revista Philosophica, no 31, 2008, pp. 6578. Agradecemos aos editores a cessão dos direitos de publicação.

1. Kant, I. Para uma paz perpétua. In: __. Gesammelte Schriften. Berlim: Preußischen Akademie der Wissenschaften, 1900 e ss, vol. VIII, p. 366. 
autor revela a heterogeneidade radical entre o direito e a ética, ou seja, entre a liberdade exterior e a liberdade interior. Esta ideia pressupõe que o direito não se preocupa em melhorar a moralidade dos indivíduos, mas simplesmente em garantir uma coexistência. Nesse caso, a força do direito neutraliza a afirmação ilimitada da liberdade, sem erradicar a maneira de ser ou disposição (Gesinnung) do ser jurídico, permitindo assim uma comunidade de seres jurídicos que sejam seres diabólicos, determinados absolutamente pela maldade. Ora, a dificuldade que levanta esta tese consiste precisamente na dificuldade de definir a dimensão normativa da legislação. A alternativa é a seguinte: ou o direito se reduz a uma técnica racional que estabelece uma ação recíproca entre os indivíduos do ponto de vista exterior, ou esta força de coação se apresenta como uma condição de progresso cujo horizonte se situa além do campo jurídico, ou seja, numa comunidade ética. Através do povo de demônios, trata-se de justificar a prioridade teleológica do direito sobre a ética. Para isso, é necessário entender de que maneira é possível conceber a ideia de um ser jurídico diabólico, para em seguida mostrar a dimensão hiperbólica dessa ideia e a sua dimensão normativa nas relações entre os indivíduos e na relação entre os Estados.

\section{O sujeito jurídico como ser diabólico: a confrontação entre Erhard e Kant}

O argumento relativo ao povo de demônios não é uma inovação kantiana. De fato, em 1795, Johann Benjamin Erhard publica, no Philosophisches Journal, uma "Apologia do diabo" ("Apoliogie des Teufels"), ${ }^{2}$ texto que considera a questão da coexistência jurídica independentemente de qualquer consideração moral. No presente contexto, a confrontação dos dois textos revela-se pertinente para explicitar os pontos de convergência e divergência entre os dois autores. Erhard formula a tese seguinte: o direito não deve ser deduzido da moral, mas da possível tolerância mútua dos apetites interessados dos homens. ${ }^{3}$ Para levar a cabo a sua demonstração,

2. Erhard, J. B. Apologie du diable. Trad. francesa de P. Secrétan. Caen: Centre de Philosophie politique et juridique, 1989.

3. Idem, p. 18. 
o autor radicaliza o sujeito jurídico para apresentá-lo como um ser determinado exclusivamente pela maldade, ou seja, como um demônio ou diabo. Não se trata aqui de pensar uma ideia sem consistência mas, bem pelo contrário, de elaborar um conceito que contém uma dimensão normativa. ${ }^{4}$ Há que admitir que este conceito não pode ser pensado a partir da experiência, na medida em que não existem sinais exteriores naturais, mas o que interessa ao autor é a análise das disposições interiores (Gesinnung). De fato, a radicalização do sujeito jurídico consiste em mostrar de que maneira uma comunidade de seres sem conhecimento da lei moral, ou seja, determinados pelo mal absoluto, é concebível.

Segundo essa metodologia, o conceito de diabo define-se como uma criatura absolutamente má, eternamente torturada, que não conhece nenhum arrependimento, procurando constantemente a infelicidade dos homens. ${ }^{5}$ A particularidade do diabo é o mal absoluto que o caracteriza, em oposição real ao bem. Não existe uma contradição entre o mal e o bem, mas uma relação entre elementos contrários como duas forças opostas que não podem convergir. A maldade, ou mal absoluto, apresenta-se como "algo real, que suprime o bem na intenção". ${ }^{6} \mathrm{O}$ ideal de maldade consiste num sujeito que age sempre em oposição ao ideal de moralidade, em que, por sua vez, ele age segundo uma intenção determinada pelo bem. Considerado como princípio material, este ideal de maldade define o carácter da intenção má segundo os momentos seguintes: ${ }^{7}$ primeiro a singularidade, que se explicita através de uma máxima que pertence exclusivamente ao ser que age determinado pelo mal absoluto, impedindo assim que outro ser possa adotar a mesma máxima; segundo, o seu próprio interesse, ou seja, a intenção que é simplesmente egoísta; terceiro, a liberdade absoluta, na qual o sujeito considera o resto - as pessoas e as coisas - como meios para o seu próprio uso. Conjugando estes três momentos, é possível então formular uma proposição inerente à

\footnotetext{
4. Idem, p. 1.

5. Idem, p. 3.

6. Idem, p. 3-4.

7. Idem, p. 10.
} 
intenção má: "Quero agir de tal maneira que o próprio Eu seja o único propósito da minha ação e apareça como o único ser livre". ${ }^{8}$ Segundo estas características, Erhard admite que uma coexistência exterior de seres diabólicos é possível a partir da faculdade de coação do direito. Relativamente a esta posição, o autor baseia-se na definição da legislação jurídica. O direito não é nada mais que a capacidade de atuar segundo máximas materiais, sem que outrem tenha qualquer legitimidade para se opôr por meio da violência. ${ }^{9}$ Isto significa então que o princípio jurídico não contempla os motivos da ação, mas apenas o estabelecimento de uma reciprocidade, ou seja, uma exigência de acordo mútuo entre os homens, ${ }^{10}$ condição necessária para introduzir uma igualdade de direitos.

Por essas razões, a obediência ao direito não requer qualquer disposição interior animada pela moral, já que se trata exclusivamente de encontrar um acordo a partir do qual os indivíduos possam garantir sua sobrevivência e sua propriedade. Esta tese traduz a ideia de um direito deduzido dos apetites interessados dos homens. A partir deste ponto, é possível formular duas consequências: por um lado, a perfeita obediência às leis do direito não se pode apresentar como uma prova de intenção moral. Bem pelo contrário, nessas condições a obediência resulta do temor que inspira a faculdade de coação do direito, representado pelo Estado, seguindo-se assim o pensamento de Hobbes. ${ }^{11} \mathrm{Se}$ os sujeitos obedecem, é precisamente porque lhes convém, já que a jurisdição impede os outros de expressarem as suas más intenções, pondo em perigo os seus bens. Por outro lado, a rigorosa aplicação do direito, quando resulta do soberano e do seu poder supremo, não é tão pouco uma prova de bondade. ${ }^{12}$ Este soberano pode de igual modo ser um demônio, porque a única contradição para ele seria o fato de todos possuírem os mesmos direitos que ele, não o fato de ele ter um direito que lhe permita estar

\footnotetext{
8. Idem, p. 10.

9. Idem, p. 17.

10. Idem, p. 17.

11. Hobbes, T. Léviathan. Trad. francesa de F. Tricaud. Paris: Sirey, 1971, caps. VI e XVI.

12. Erhard, J. B. Apologie du diable, p. 18.
} 
acima dos sujeitos ou servir aos seus próprios interesses. Erhard situa-se aqui do ponto de vista do direito positivo, o direito que resulta do arbítrio do soberano.

No texto de 1785, Kant situa-se no mesmo horizonte problemático que Erhard. De fato, trata-se de saber se a coexistência dos sujeitos jurídicos pode excluir qualquer consideração moral. De igual modo que Erhard, Kant recorre ao conceito de ser diabólico para radicalizar a heterogeneidade entre o sujeito jurídico e o sujeito determinado pela lei moral. No texto $A$ religião nos limites da simples razão, de 1793, o autor define o ser diabólico como o sujeito cuja intenção consiste em admitir o mal como mal, ou seja, afirmar a maldade absoluta como motivo nas suas próprias máximas. ${ }^{13} \mathrm{O}$ que caracteriza o demônio é precisamente a ideia de que a maldade não é um abandono de princípios morais ditados pela razão normativa, mas uma propriedade de sua disposição. Através desta hipérbole, o objetivo de Kant é insistir sobre a eficácia da legislação jurídica para constranger os indivíduos a obedecer às leis comuns exteriores. O que distingue a lei jurídica da lei de virtude é a amplitude do dever: "quanto mais o dever é amplo, mais é imperfeita a obrigação de atuar para o homem”. ${ }^{14} \mathrm{O}$ dever jurídico afirma-se como dever perfeito na medida em que não aceita nenhuma exceção relativa à obediência à lei, enquanto o dever de virtude concede ao livre arbítrio uma certa latitude em relação à execução da lei. A pertinência desta tese é mostrar que para sair de um estado de natureza, onde não existe um poder político hierarquicamente superior e capaz de impor leis comuns exteriores, o meio mais eficaz é a imposição de uma legislação jurídica capaz, através da sua força de coação, de neutralizar o egoísmo de cada um. Em outras palavras, o homem obedece primeiro a uma força exterior antes de obedecer à sua lei moral, e, por isso, o fato de entrar num estado civil representa para ele o único meio de garantir sua vida e seus bens. A partir deste ponto, temos de reconhecer que a coexistência das liberdades exteriores não resulta de uma

13. Kant, I. A religião nos limites da simples razão. In: Gesammelte Schriften, vol. VI, p. 37

14. Kant, I. Metafísica dos costumes. In: 390. 
decisão da moralidade de cada um, mas de uma convergência de interesses. Recordamos que o direito se aplica apenas à relação formal dos arbítrios, exigindo assim uma adesão exterior e não uma adesão íntima. ${ }^{15}$ Para constituir uma coexistência de liberdades, a legislação jurídica impõe uma igualdade de ação e de reação entre os indivíduos, ou seja, uma coação recíproca. ${ }^{16}$

No entanto, apesar dessas convergências, o propósito de Kant difere das posições de Erhard. De fato, o autor da Apologia do diabo insiste sobre a autonomia do direito em relação à moral, enquanto Kant explicita a heterogeneidade entre o direito e as leis de virtude. Este ponto é decisivo por duas razões: por um lado, a oposição kantiana não se dá entre o direito e a moral, mas entre o direito e a ética. No texto de 1795, Kant nota que a moral é também considerada como uma teoria do direito, ${ }^{17}$ o que sugere que este é, ao lado da ética, uma das divisões da moral definida como sistema dos deveres em geral. Esta inovação conjuga-se com uma alteração terminológica operada por Kant. Na Metafísica dos costumes, a moral define-se como sistema de leis normativas incondicionadas, que se aplicam ao arbítrio a partir de um imperativo categórico. ${ }^{18}$ Por esse motivo, não existe autonomia do direito em relação à moral, na medida em que a lei de liberdade jurídica é considerada como uma lei moral. Nessas condições, as leis jurídicas se opõem à ética definida como lei moral, que se aplica à máxima da ação e requer, assim, uma adesão íntima entre o ser sensível e o ser inteligível. ${ }^{19}$ Por outro lado, este argumento, ao contrário daquele de Erhard, situa-se do ponto de vista teleológico: trata-se de saber como é possível tirar benefício do mecanismo da natureza para encontrar uma convergência de interesses e constituir um estado pacífico de legislação. ${ }^{20}$ Isto significa que o direito não tem por objetivo moralizar os homens, mas simplesmente instaurar uma coexistência exterior, uma igualdade de direitos aplicável às ações. $\mathrm{O}$ progresso da humanidade inscreve-se

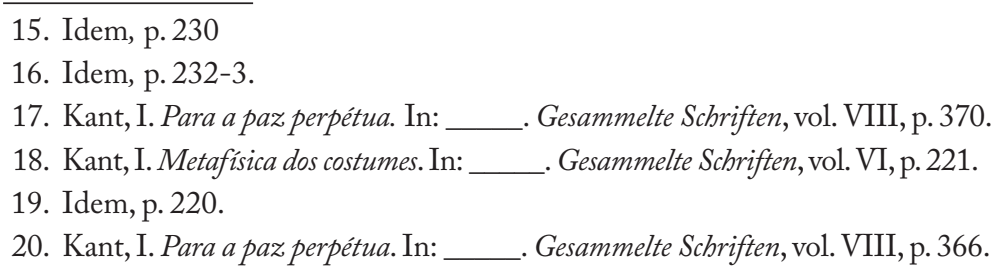


no progresso do direito e, mais rigorosamente, no progresso das instituições e constituições jurídicas. Antes de nos interessarmos pelas várias dimensões desse progresso, é necessário primeiro explicar a dimensão hiperbólica do povo de demônios, ponto decisivo para entender que uma conversão do homem ao bem é sempre possível, o que legitima o postulado de um progresso da humanidade.

\section{A dimensão hiperbólica do povo de demônios: a possibilidade do progresso.}

Para demonstrar o carácter hiperbólico do povo de demônios, ou seja, a dimensão que procede por excesso e que, neste caso, não corresponde a nenhum objecto na experiência, é necessário reler as diferentes observações formuladas por Kant relativamente à presença do mal no ser humano. Em uma nota do texto Metafísica dos costumes, de 1795, o autor revela que os vícios diabólicos do homem, tal como as virtudes angélicas, não são nada mais que os Ideais de um máximo concebido como medida para a comparação dos diversos graus de moralidade. ${ }^{21}$ Estes dois conceitos, definidos como ideias da própria razão nunca são objectos duma experiência possível. Têm um uso normativo, regulador, mas em nenhum caso chegam a ter uma realidade objetiva. Isso nos leva a considerar que o homem é um ser intermediário entre esses dois extremos, sem pertencer a nenhum deles, e, assim, tem de ser encontrado um outro fundamento do mal no homem.

A posição de Kant relativamente ao fundamento do mal adota duas exigências essenciais: por um lado, o mal não pode ser deduzido de uma perversão da própria razão humana, o que implica que a máxima do mal nunca se pode apresentar como único fundamento subjetivo de nossas ações. ${ }^{22} \mathrm{~A}$ razão normativa legisladora não pode ser corrupta na medida em que, dando a conhecer a cada homem a lei moral como um fato, não pode destruir a autoridade dessa mesma lei e negar assim a obrigação que dela se deduz: conceber-se como um ser que age livremente e,

21. Kant, I. Metafisica dos costumes. In: Gesammelte Schriften, vol. VI, p. 461.

22. Kant, I. A religião nos limites da simples razão. In: vol. VI, p. 35. 
ao mesmo tempo, como um ser capaz de excluir o conhecimento da lei moral, revela-se contraditório. ${ }^{23}$ Neste caso, o homem seria completamente determinado por leis de natureza e não poderia manifestar qualquer liberdade. Por outro lado, quaisquer que sejam as máximas de sua ação, inclusive as que se apresentam como princípios subjetivos de maldade, o homem nunca renuncia à lei moral. O homem mais detestável tem conhecimento da lei moral, mesmo se, como ser livre, decide transgredi-la. Para entender este ponto, podemos nos referir a uma nota da Crítica da faculdade do juizo, no § 87. Kant indica que o ser humano não é um ser que age segundo as leis morais, mas um ser que está submetido a elas: no primeiro caso, o homem seria um ser cuja ação está sempre em conformidade com a lei moral, manifestando assim uma vontade santa - o que se revela impossível sem fazer abstração da sua condição de ser sensível. No segundo caso, que corresponde à condição do homem como ser sensível racional, cada um tem conhecimento da lei moral, mas isso não implica que siga as indicações da razão normativa: a liberdade do homem pode exercer-se também para o lado do mal. ${ }^{24}$

A partir dessa ideia torna-se possível entender que o fundamento do mal no homem não se conjuga com a supressão da lei moral, mas resulta, pelo contrário, de um desvio em relação ao que indica a razão normativa: "o homem, insiste Kant, nunca consente o mal na sua própria pessoa; por conseguinte, na realidade a maldade nunca resulta de princípios, mas do abandono destes". ${ }^{25}$ Kant explicita este ponto em uma nota de um texto de 1796: Anúncio da próxima conclusão de um tratado de paz perpétua em filosofia. Ao contrário do mal físico (malum), que resulta da condição de sermos submetidos às leis de natureza, o mal moral (pravum) conjuga-se com a lei de liberdade. ${ }^{26}$ Do ponto de vista da liberdade, o mal resulta de uma decisão inteligível, relativamente à sua própria interioridade.

23. Idem p. 35.

24. Kant, I. Crítica da faculdade do juizo. In: p. 448-9. Gesammelte Schriften, vol. V,

25. Kant, I. Antropologia de um ponto de vista pragmático. In: Schriften, vol. VII, p. 294.

26. Kant, I. Anúncio da próxima conclusão de um tratado de paz perpétua em filosofia. In: . Gesammelte Schriften, vol. VIII, p. 415. 
Mesmo que o ser sensível racional tenha uma disposição (Anlage) para o bem, na sua existência é uma inclinação (Hang) ao mal que se manifesta. Essa decisão é uma escolha inteligível que adota por máxima suprema o mal e o torna radical. No entanto, não se deve concluir da expressão "mal radical" que a maldade seja um princípio subjetivo de determinação que exclui a lei moral. Mesmo que o autor afirme que a intenção radical é uma maneira inata de ser, ${ }^{27}$ não se pode atribuí-la a qualquer determinismo. $\mathrm{O}$ termo "inato" referese à intemporalidade do ato inteligível, através do qual o homem escolhe livremente a máxima suprema de suas acções: essa maneira de ser é considerada o fundamento anterior a qualquer exercício da liberdade na experiência e representada no homem desde o seu nascimento, sem que este seja a sua causa. Afirmar que o mal é uma inclinação natural equivale a dizer que se trata de uma natureza que o próprio homem deu a si mesmo. Por isso o ser humano aparece como um ser curvado, inclinado para o seu egoísmo.

A reflexão de Kant mantém precisamente a relação entre o mal e a liberdade para responsabilizar o homem. $\mathrm{Na}$ medida em que o mal resulta de uma decisão inteligível, o homem determinase por si próprio e define então as máximas secundárias a partir da máxima suprema: "Esse mal é radical porque corrompe o fundamento de todas as máximas". ${ }^{28} \mathrm{~A}$ radicalidade desta decisão não suprime nem a lei moral nem a liberdade que lhe é inerente. De fato, o pior criminoso não suprime, nas suas ações, a autoridade da razão normativa legisladora. $\mathrm{O}$ exemplo do regicídio formulado por Kant revela-se aqui pertinente: ${ }^{29}$ a transgressão da lei moral só pode ser explicada como efeito de uma máxima que adota o crime por princípio subjetivo, pois assim se pode considerá-lo um ser livre. No entanto, não se trata aqui de uma máxima adotada como princípio objetivo e expressando um valor universal, mas de uma máxima que transgride a lei moral. Esta transgressão pode chegar ao ponto em que devemos perguntar-nos se não se trata, mais do

27. Kant, I. A religião nos limites da simples razão. In: Gesammelte Schriften, vol. VI, p. 22.

28. Idem, p. 37.

29. Kant, I. Metafísica dos costumes. In: 321-2. . Gesammelte Schriften, vol. VI, p. 
que de um desvio ou falta, de um divórcio, já que o indivíduo adota por princípio agir sempre contra a lei moral, apesar de reconhecer a autoridade e a validade da razão legisladora..$^{30} \mathrm{O}$ que significa que a lei moral, mesmo não sendo respeitada, não desaparece da interioridade do ser sensível racional.

Admitindo que o mal se manifesta no homem como uma inclinação, não se pode aceitar que o mal obedece ao mesmo grau de consciência. Para julgar acerca da imputabilidade do indivíduo, é então necessário distinguir três graus distintos do mal: primeiro a fragilidade, definida como inaptidão para seguir na prática a lei moral que a vontade adota na sua máxima. A fragilidade diferencia-se então da impureza, em que o ser razoável cumpre uma ação boa não por respeito à lei moral, mas mediante outros motivos que expressam o seu egoísmo, reduzindo assim a virtude a uma simples aparência. A maldade ou corrupção, que é o grau mais elevado do mal, consiste numa inversão da ordem moral dos motivos que o homem admite nas suas máximas. $\mathrm{O}$ interesse desta graduação do mal é mostrar que a ideia de um ser diabólico é contraditória com a ideia da liberdade, o que explica a dimensão hiperbólica do povo de demônios. Isso implica um limite na liberdade para o mal: um ser livre não tem o poder de libertar-se da lei moral e escolher o mal pelo mal. Situado entre uma vontade bruta, que corresponde ao animal determinado pela sensibilidade, e uma vontade diabóli$c a$, do ser determinado pelo mal, o homem exerce a sua liberdade entre estes dois extremos: a vontade humana nem é absolutamente moral, já que pode optar pelo mal, nem absolutamente má, porque a razão moral mantém a sua autoridade.

É precisamente essa tese que permite pensar na possibilidade de uma conversão que consiste no restabelecimento da ordem moral dos motivos. Embora esta conversão se opere como uma revolução, através da adoção radical do bem nas suas máximas, para o ser humano ela se manifesta como uma progressão infinita. Ora, esta progressão torna-se efetiva apenas através do direito e do melhoramento das instituições jurídicas. Trata-se então de conce-

30. Idem, p. 322. 
ber as diferentes fases do progresso através da presença do mal nas relações entre os indivíduos e entre os Estados.

III. A questão jurídica: como neutralizar o mal a nível exterior?

Recordamos que o direito, através da sua força de coação, permite neutralizar a expressão ilimitada da liberdade natural dos indivíduos. Isso significa que a legislação jurídica é capaz de neutralizar o mal, ou seja, impedir que ele se manifeste a nível exterior, mas em nenhum caso é capaz de erradicá-lo, já que o direito não se aplica à interioridade do sujeito jurídico. Ora, dois pontos revelamse aqui decisivos: por um lado, a hipérbole do povo de demônios apresenta-se para Kant como um exemplo da teleologia ordenada pelo mecanismo da natureza. O homem quer a concórdia, mas a natureza procura a discórdia, ${ }^{31}$ de modo que os indivíduos, nos seus diferentes conflitos de interesses, tornem-se ativos e entrem em um estado civil onde existem leis comuns exteriores. Nestas condições, Kant admite que não se pode contar com a dimensão moral dos indivíduos para progredir, na medida em que a liberdade que manifestam está a serviço de interesses patológicos e não de interesses da razão. Por esse motivo, o sujeito jurídico pode, de maneira hiperbólica, apresentar-se como um ser diabólico contra o qual o direito opõe a força das leis do direito público. Por outro lado, no texto de 1795 Kant não limita a hipérbole do povo de demônios à questão da paz interior do Estado, mas a inscreve também, por meio da questão da paz exterior, na relação entre os Estados. Mesmo se o autor não tematiza este argumento de maneira mais explícita, é possível pensar que o povo de demônios se pode referir tanto à questão do direito político como ao direito cosmopolítico. Nesse texto, em que trata do povo de demônios, Kant termina a sua análise referindo-se à exigência de instaurar princípios de direito que permitam ao Estado garantir "uma paz exterior e mesmo interna". ${ }^{32} \mathrm{O}$ que está aqui implícito é a ideia de que os Estados

31. Kant, I. Idéia de uma história universal de um ponto de vista cosmopolita. In: . Gesammelte Schriften, vol. VIII, p. 21.

32. Kant, I. Para a paz perpétua. In: . Gesammelte Schriften, vol. VIII, p. 367. 
podem estar civilizados juridicamente do ponto de vista interno, ou seja, nas relações entre os indivíduos, mesmo que as relações entre Estados permaneçam em um estado de natureza. Dito por outras palavras, podemos levantar aqui a hipótese de os Estados poderem ser diabólicos, já que não implicam nenhuma dimensão ética. Este caso é possível considerando-se o ponto de vista do direito positivo, em que as leis estão definidas pelo arbítrio do soberano e o direito pode ser um conjunto de leis arbitrárias e contingentes. ${ }^{33}$ No texto de 1795, mais precisamente no "Primeiro Apêndice", Kant confirma a nossa tese: a perversidade enraizada nos indivíduos que vivem em uma sociedade civil é neutralizada pelas leis coercitivas do direito, mas manifesta-se plenamente nas relações exteriores entre os Estados, onde a luta pela soberania é constante. ${ }^{34}$

Relativamente a essas duas dimensões, Kant insiste na ideia de que o progresso na conduta exterior não pode ser deduzido por meio de uma reforma moral dos homens. Pelo contrário, somente uma boa constituição pode produzir uma reforma moral, o que implica que o motor do progresso é exclusivamente jurídico. $\mathrm{O}$ direito revela-se então, na reflexão kantiana, tanto como efeito do mecanismo da natureza quanto como meio necessário do progresso da humanidade. A partir destes elementos, é necessário saber quais são os meios pelos quais o direito, tanto a nível interior como exterior, pode neutralizar o mal e contribuir para o progresso da razão. Em uma nota das Reflexóes sobre a filosofia do direito, Kant situa o motor do progresso jurídico na ideia de um governo deduzido do direito público, ou seja, de um sistema de leis aplicadas a um povo, conformes ao direito de natureza (Naturrecht), que se define como um conjunto de leis deduzidas da razão normativa: "Um governo conforme tanto ao direito político como ao direito cosmopolítico é possível numa constituição". ${ }^{35} \mathrm{O}$ ponto decisivo consiste na instauração de um modo de governo republicano, cuja constituição exclui o estabelecimento de um direito positivo para

33. Kant, I. Metafísica dos costumes. In: Gesammelte Schriften, vol. VI, p. 237.

34. Kant, I. Para a paz perpétua. In: . Gesammelte Schriften, vol. VIII, p. 375, nota.

35. Kant, I. Reflexionen, no 8077. In: Gesammelte Schriften, vol. XIX, p. 608-9. 
fundamentar-se apenas nas leis normativas a priori da razão. Neste caso, um tal governo opõe-se ao despotismo de maneira a permitir um verdadeiro progresso das instituições jurídicas. Considerar-se como um membro da sociedade cosmopolítica, unido às outras pessoas de acordo com o direito político, revela-se "como a ideia mais sublime que o homem pode ter do seu destino" ${ }^{36}$ Nestas condições, um único exemplo desse Estado pode servir de sinal precursor suficiente para dar esperanças quanto à possibilidade dessa união. Esse Estado constitucional seria assim a garantia de paz para os Estados vizinhos, algo que não estaria garantido num Estado conforme a um direito arbitrário. Contra o mal dos indivíduos e dos Estados que procuram os seus próprios interesses, Kant não opõe inicialmente uma conversão da máxima suprema do mal para o bem, mas formula a ideia de que existe uma disposição moral do conceito de direito entendido como poder de obrigação para o gênero humano. ${ }^{37} \mathrm{~A}$ dimensão "moral" corresponde aqui às leis normativas a priori da razão que se impõem segundo a forma de um imperativo categórico, aplicado aqui apenas à coexistência exterior das liberdades. Trata-se de uma ideia do direito que fundamenta uma constituição cujos princípios impendem não só nos conflitos, mas garantem uma progressão constante. Não se pode prognosticar a realização de uma tal exigência, mas o que fica bem claro, para Kant, é que os homens perseguirão esse objectivo até poderem realizá-1o. ${ }^{38}$

Essa constituição republicana revela-se pertinente tanto a nível da paz interior como da exterior, para neutralizar o mal na reciprocidade dos indivíduos. Assim como a violência generalizada conduz um povo a submeter-se à lei pública e entrar em uma constituição civil do Estado, a violência que resulta dos conflitos interestatais conduz a entrar numa constituição cosmopolita, que adota a forma de uma federação. Estas duas dinâmicas obedecem à mesma exigência: já que o mal se manifesta na oposição recíproca de inclinações, a única maneira de garantir os interesses de cada indivíduo ou de cada Estado consiste no ingresso em um

36. Idem, ibidem.

37. Idem, ibidem.

38. Idem, ibidem. 
estado jurídico. ${ }^{39}$ Notamos aqui que esta exigência, mais uma vez, não resulta de qualquer disposição da moralidade, mas de uma convergência de interesses que a nível exterior corresponde a uma dimensão moral jurídica. É a partir da ideia de um governo republicano que o direito se afirma como motor do progresso da humanidade, tendo como horizonte um estado jurídico de paz.

No entanto, a eficácia jurídica contra o mal está limitada à comunidade jurídico-civil, se bem que esta comunidade se possa estender a uma relação interestatal e cosmopolita. O que significa que as raízes do mal, na realidade do ser humano, só podem ser erradicadas através de uma comunidade ético-civil no seio da qual a coexistência, antes de ser exterior, é interior, ou seja, o ser sensível concorda com o ser inteligível. Neste quadro, a pertinência de Kant consiste em constituir o direito como meio de progresso e de sua própria superação em direção a uma comunidade fundada sobre leis de virtude, não sobre leis de coação.

\section{Bibliografia}

ERHARD, J. B. Apologie du diable. Trad. francesa de P. Secrétan. Caen: Centre de Philosophie politique et juridique, 1989.

HOBBES, T. Léviathan. Trad. francesa de F. Tricaud. Paris: Sirey, 1971.

KANT, I. Gesammelte Schriften. Berlim: Preußischen Akademie der Wissenschaften, 1900 e ss.

39. Kant, I. Sobre a expressão corrente: isto pode ser correto na teoria, mas nada vale na prática. In: . Gesammelte Schriften, vol. VIII, p. 310. 